\title{
TRANSLOCAÇÃO BACTERIANA PARA O PULMÃO NA ICTERÍCIA OBSTRUTIVA EXPERIMENTAL EM RATOS
}

\author{
BACTERIAL TRANSLOCATION TO THE LUNG IN OBSTRUCTIVE \\ JAUNDICE IN RATS
}

\author{
Aldo da Cunha Medeiros, TCBC-RN ${ }^{1}$ \\ Maria Goretti Freire de Carvalho ${ }^{2}$ \\ Antônio Medeiros Dantas Filho,RCBC-RN ${ }^{3}$ \\ Francisco Edilson Leite Pinto Jr,TCBC-RN ${ }^{3}$ \\ Robson Macedo Filho ${ }^{4}$ \\ Raquel Araújo Costa Uchôa ${ }^{4}$
}

\begin{abstract}
RESUMO: Objetivo: Tem sido demonstrado que a icterícia obstrutiva provoca depressão do sistema imunológico, mudança no padrão de colonização bacteriana dos intestinos e passagem de bactérias da luz intestinal para a circulação porta e sistêmica. Estudo experimental em ratos procurou observar a possibilidade de translocação bacteriana para os pulmões após a ligadura do colédoco. Método: Foram utilizados 20 ratos Wistar pesando de 178 a $215 \mathrm{~g}$, separados aleatoriamente em dois grupos iguais. Nos ratos do grupo I foi feita a ligadura do colédoco e nos do grupo II apenas a manipulação do colédoco com pinça atraumática (sham operation). No sétimo dia de observação os animais foram mortos com superdose de anestésico, sangue foi colhido para dosagem de bilirrubinas e os pulmões ressecados sob condições assépticas. Metade de cada pulmão foi homogeneizada e semeada em meios de cultura ágar McConkey e ágar sangue. A outra metade serviu para exame histopatológico -coloração hematoxilina e eosina. Os dados foram analisados pelo teste t, com significância 0,05 . Resultados: revelaram bilirrubina total em média $18,7 \pm 3,6$ no grupo I e $0,7 \pm 0,2$ no grupo II. No grupo I foram isoladas colônias de Klebsiela sp nos pulmões de $30 \%$ dos animais e E. coli em $20 \%$, e os escores histopatológicos atingiram a média $6,2 \pm 2,08$. No grupo II não foram detectadas bactérias nos pulmões e os escores do exame histopatológico atingiram 1,8 $\pm 1,16$. A diferença dos dados analisados mostrou-se significativa $(\mathrm{p}<0,05)$. Conclusões: Concluiu-se que a icterícia obstrutiva por ligadura do colédoco em ratos provocou translocação de germes Gram-negativos para os pulmões e resultou em alterações histopatológicas significativas.
\end{abstract}

Descritores: Translocação bacteriana; Pulmões; Icterícia obstrutiva.

\section{INTRODUÇÃO}

Os principais componentes fisiopatológicos da obstrução biliar extra-hepática são, em primeiro lugar, o au- mento da pressão biliar intraductal e, segundo, a interrupção do fluxo para o intestino. A fagocitose dos leucócitos encontra-se deprimida na icterícia obstrutiva ${ }^{1,2}$, e tem sido demonstrada a passagem de bactérias entéricas viáveis para

1. Doutor em Cirurgia, Professor Adjunto IV de Técnica Operatória e Cirurgia Experimental, Chefe do Núcleo de Cirurgia Experimental da UFRN, Pesquisador nível I do CNPq.

2. Professora Doutora do Departamento de Patologia da UFRN.

3. Mestre em Cirurgia, Professor Assistente do Departamento de Cirurgia da UFRN

4. Estudantes Bolsistas de Iniciação Científica do CNPq.

Recebido em $31 / 7 / 2000$

Aceito para publicação em 14/11/2000

Trabalho realizado no Núcleo de Cirurgia Experimental Prof. Travassos Sarinho, e no Departamento de Cirurgia da Universidade Federal do Rio Grande do Norte - UFRN. Apoiado pelo CNPq. 
órgãos extra-intestinais considerados estéreis em estudos experimentais ${ }^{4,5}$. Ambos os mecanismos provavelmente se complementam no desenvolvimento da endotoxemia sistêmica, que continua, juntamente com a infecção, como as principais causas de morbidez e mortalidade em pacientes com icterícia obstrutiva ${ }^{6,7}$. Alguns estudos têm mostrado que ocorre transposição de endotoxinas da luz intestinal para a circulação portal no indivíduo ictérico, e estima-se que há migração de bactérias através da barreira mucosa para órgãos como fígado, baço, pâncreas e linfonodos mesentéricos ${ }^{8,9}$, processo que recebeu a denominação de translocação bacteriana. Teoricamente, a bactéria, ao ultrapassar a barreira mucosa, atinge os linfonodos mesentéricos, daí segue para o ducto torácico e pode atingir os pulmões, seguindo seu caminho natural.

Dando prosseguimento à linha de pesquisa relacionada a repercussões da icterícia em órgãos a distância, foi avaliada, em estudo experimental em ratos, a possibilidade de ocorrência de translocação bacteriana para os pulmões após ligadura do colédoco.

\section{MÉTODO}

Foram utilizados 20 ratos Wistar, pesando de 178 a $215 \mathrm{~g}$, separados aleatoriamente em dois grupos. Os animais, observados em gaiolas individuais, utilizaram água e alimentação ad libitum. Durante o período de observação manteve-se microambiente com controle de temperatura, umidade e partículas, com alternância de 12 horas de claro-escuro. A anestesia foi realizada com pentobarbital sódico intraperitoneal na dose de $20 \mathrm{mg} /$ $\mathrm{kg}$, utilizando-se técnica asséptica.. Laparotomia mediana de $3 \mathrm{~cm}$, foi feita a partir do apêndice xifóide. Demais procedimentos: no grupo $I(n=10)$ : identificação do colédoco e ligadura do mesmo com fio de seda no 0000 o mais próximo possível do fígado, para que fosse evitada a lesão do ducto pancreático. Nos animais do grupo II ( $\mathrm{n}=10)$ a "porta hepatis" foi identificada e apenas manipulada com pinça de dissecção atraumática (sham operation). Síntese da parede abdominal com dois planos de sutura em pontos separados de monofilamento de nylon $\mathrm{n}^{\mathrm{o}} 0000$.

Após sete dias de observação aplicou-se dose letal de anestésico por via intramuscular. Relaparotomizados com técnica asséptica, uma amostra de $5 \mathrm{ml}$ de sangue foi colhida através de punção cardíaca para dosagem de bilirrubinas. Ressecados os pulmões, separando-se metade de cada órgão para exame microbiológico e a outra metade para exame histopatológico. Os fragmentos destinados ao exame microbiológico sofreram processo de homogeneização e processou-se a semeadura seletiva em meio de cultura ágar McConkey para detecção de Gram-negativos e em meio ágar sangue para Gram-positivos. As placas foram incubadas a $37{ }^{\circ} \mathrm{C}$ e examinadas após 24 e $48 \mathrm{~h}$. Os mi- crorganismos identificados e as colônias individuais quantificadas em unidades por grama de tecido. O exame histopatológico foi realizado através da coloração pela hematoxilina-eosina e pelo Gram para identificação de bactérias. Fez-se a quantificação das alterações histopatológicas de acordo com suas intensidades de zero a + três, contabilizando-se o total de escores de cada grupo de acordo as somas obtidas para cada animal.

Os dados foram analisados pelo teste $t$, considerando-se significância de 0,05.

\section{RESULTADOS}

Todos os animais sobreviveram. Os do grupo I apresentavam-se francamente ictéricos ao término dos sete dias de observação. A bilirrubina total apresentou média de $6,1 \pm 3,6 \mathrm{mg} / 100 \mathrm{ml}$ no grupo I e $0,7 \pm 0,2 \mathrm{mg} /$ $100 \mathrm{ml}$ no grupo II (diferença significativa $\mathrm{p}<0,05$ ). Nos exames de cultura do grupo I isolaram-se colônias de Klebsiela sp no parênquima pulmonar de três dos 10 (30\%) ratos e E. coli em dois (20\%) deles (Tabela 1). Os demais animais desse grupo não apresentaram translocação. No grupo II (controle) observou-se ausência de germes em todos os animais no mesmo órgão examinado, tanto na cultura específica para Gram-negativos quanto para Gram-positivos. Os resultados histopatológicos estão resumidos nas Tabelas 2 e 3 . A Figura 1 mostra o aspecto normal de pulmão do rato número 1 do grupo II (controle). Leucócitos nos septos pulmonares com intensidade 3 podem ser observados na $\mathrm{Fi}$ gura 2, que corresponde ao rato número 2 do grupo I. A Figura 3 mostra macrófagos impregnados de bile nos alvéolos pulmonares.

Outros achados histopatológicos: no grupo I notaram-se outras alterações histopatológicas em alguns animais, que não estão listadas na Tabela 2. Assim, nos ratos de números 3 e 4 foi observada hiperplasia linfóide e o número 6 apresentava bactérias Gram-negativas nos alvéolos (Figura 4). Os ratos 7 e 8 apresentavam histiócitos com pigmento biliar em seu citoplasma. No grupo II (controle) observamos as seguintes alterações adicionais: congestão septal leve (intensidade 1) em cinco animais, presença de histiócitos nos alvéolos em dois e hemorragia alveolar em um rato.

Tabela 1

Incidência de translocação bacteriana para os pulmões

\begin{tabular}{l|l|l}
\hline & $\begin{array}{c}\text { E. coli } \\
\text { No }(\%)\end{array}$ & $\begin{array}{c}\text { Klebsiela sp } \\
\text { No }(\%)\end{array}$ \\
\hline Grupo I $(\mathrm{n}=10)$ & $2 / 10(20 \%)$ & $3 / 10(30 \%)$ \\
Grupo II $(\mathrm{n}=10)$ & $0 / 10$ & $0 / 10$ \\
\hline
\end{tabular}


Tabela 2

Achados histopatológicos do grupo I (experimental): as alterações detectadas estão expressas em intensidades de 0 a 3 , que somadas se traduzem em escores*

\begin{tabular}{|c|c|c|c|c|c|}
\hline Rato $n^{\circ}$ & $\begin{array}{c}\text { Leucócitos nos } \\
\text { vasos calibrosos }\end{array}$ & $\begin{array}{l}\text { Leucócitos nos } \\
\text { septos }\end{array}$ & $\begin{array}{l}\text { Leucócitos nos } \\
\text { alvéolos }\end{array}$ & Abscessos & $\begin{array}{c}\text { Total } \\
\text { de escores }\end{array}$ \\
\hline 1 & 2 & 3 & 0 & 0 & 5 \\
\hline 2 & 3 & 3 & 1 & 0 & 7 \\
\hline 3 & 1 & 2 & 2 & 0 & 5 \\
\hline 4 & 2 & 1 & 0 & 0 & 3 \\
\hline 5 & 2 & 2 & 3 & 3 & 10 \\
\hline 6 & 2 & 2 & 3 & 2 & 9 \\
\hline 7 & 3 & 1 & 2 & 2 & 8 \\
\hline 8 & 2 & 2 & 1 & 0 & 5 \\
\hline 9 & 2 & 1 & 2 & 0 & 5 \\
\hline 10 & 3 & 2 & 0 & 0 & 5 \\
\hline
\end{tabular}

Total dos escores

62

Média $\pm D P$

$6,2 \pm 2,08$

Tabela 3

Achados histopatológicos do grupo II (controle)*

\begin{tabular}{l|c|c|c|c|c}
\hline & Leucócitos nos & Leucócitos nos & Leucócitos nos \\
Rato $n^{\circ}$ & vasos calibrosos & septos & Total \\
\hline
\end{tabular}

\begin{tabular}{|c|c|c|c|c|c|}
\hline 1 & 0 & 0 & 0 & 0 & 0 \\
\hline 2 & 0 & 0 & 1 & 0 & 1 \\
\hline 3 & 0 & 1 & 0 & 0 & 1 \\
\hline 4 & 0 & 1 & 0 & 0 & 1 \\
\hline 5 & 1 & 2 & 0 & 0 & 3 \\
\hline 6 & 1 & 2 & 2 & 0 & 4 \\
\hline 7 & 0 & 1 & 0 & 0 & 1 \\
\hline 8 & 1 & 0 & 1 & 0 & 2 \\
\hline 9 & 0 & 1 & 2 & 0 & 3 \\
\hline 10 & 1 & 0 & 1 & 0 & 2 \\
\hline
\end{tabular}

Total dos escores

Média $\pm D P$

$1,8 \pm 1,16$

*A comparação das médias dos escores entre os grupos I e II revelou deferença significante ( $p<0,05)$.

\section{DISCUSSÃo}

Os pacientes ictéricos que são submetidos a procedimentos diagnósticos invasivos ou a intervenções cirúrgicas estão sujeitos a grande risco de complicações peroperatórias e mortalidade considerável ${ }^{10}$. Sepse por Gram-negativos constitui a grande causa dessa morbidez e mortalidade, mas a disfunção renal, a coagulopatia e a hemorragia digestiva têm sido reconhecidas como componentes importantes ${ }^{5,11,12}$. Outros estudos têm comprovado a endotoxemia e a translocação bacteriana para órgãos digestivos extra-intestinais, em diversas circunstâncias em que ocorre infecção intestinal ou estados de sepse ${ }^{13,14,15,16,17}$.
Entretanto, a literatura tem registrado raras evidências de translocação bacteriana para os pulmões em casos de icterícia obstrutiva. Estudo realizado em ratos revelou translocação bacteriana para o pulmão em $36 \%$ de animais ictéri$\cos$ examinados ${ }^{17}$, fato que foi confirmado no presente trabalho, que evidenciou translocação em 50\% dos animais submetidos à ligadura do colédoco.

Duas hipóteses procuram explicar o mecanismo de endotoxemia sistêmica na icterícia obstrutiva. Nos mamíferos o grande reservatório de germes Gram-negativos é o trato digestivo, mais especificamente o cólon. Sob condições fisiológicas normais, a barreira mucosa do intestino é impermeável para a passagem de bactérias para o meio esté- 


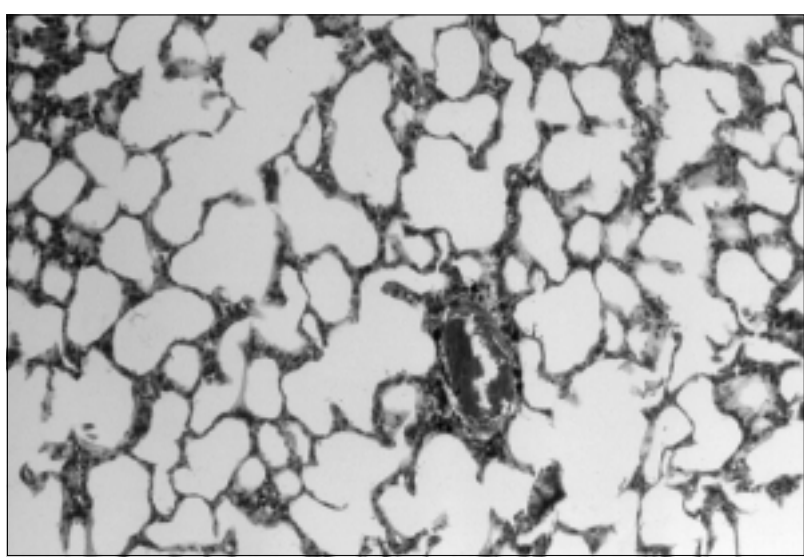

Figura1 - Aspecto histológico de pulmão normal do rato $n^{\circ} 1$ do grupo II (controle). 20X.

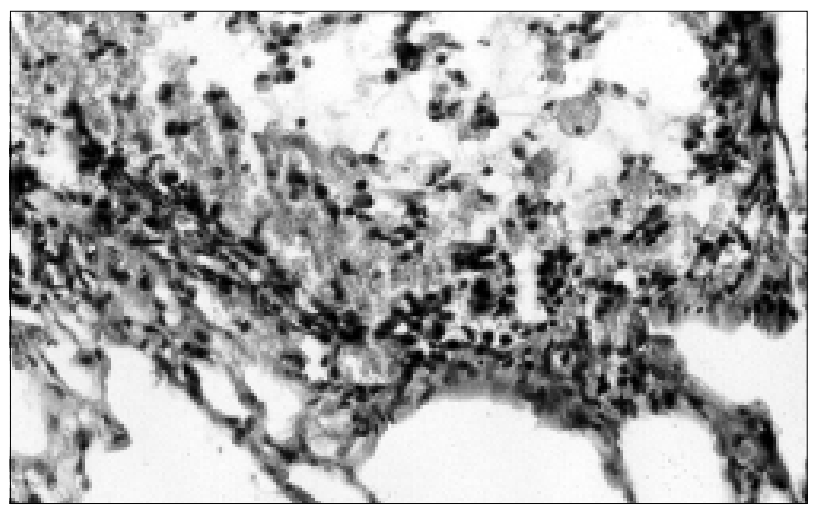

Figura 3 - Os macrófagos presentes nos alvéolos de animal do grupo I apresentam pigmento biliar em seu interior. $40 X$

ril da cavidade peritoneal, circulação porta e outros órgãos como fígado, pulmões e baço. As células de Kupffer e fagócitos mononucleares estão estrategicamente localizadas no sistema venoso porta para a seqüestração e eliminação de bactérias e endotoxinas. Qualquer distúrbio funcional ou estrutural na barreira mucosa e/ou na população das células de Kupffer, resultará na passagem de bactérias e endotoxinas para o fluxo sangüíneo da veia porta e subseqüentemente para a circulação sistêmica, normalmente estéreis. Tem sido demonstrado que na icterícia obstrutiva experimental ocorre aumento da população bacteriana intestinal ${ }^{18}$ e alterações morfológicas da mucosa, induzindo a translocação bacteriana ${ }^{3,4}$.

A endotoxemia na vigência de processos obstrutivos da árvore biliar agrava o prognóstico dos operados. Esse fenômeno pode ser secundária à ausência de sais biliares na luz intestinal. Estudos in vitro têm demonstrado que ácidos biliares não conjugados normalmente inibem o crescimento de germes Gram-negativos, sugerindo que tais substâncias influem no tipo de colonização bacteriana do intestino ${ }^{6,19,20}$. Deitch et $\mathrm{al}^{3}$ observaram populações de germes Gram-negativos 100 vezes maior no ceco de camundongos submetidos à ligadura do colédoco do que nos con-

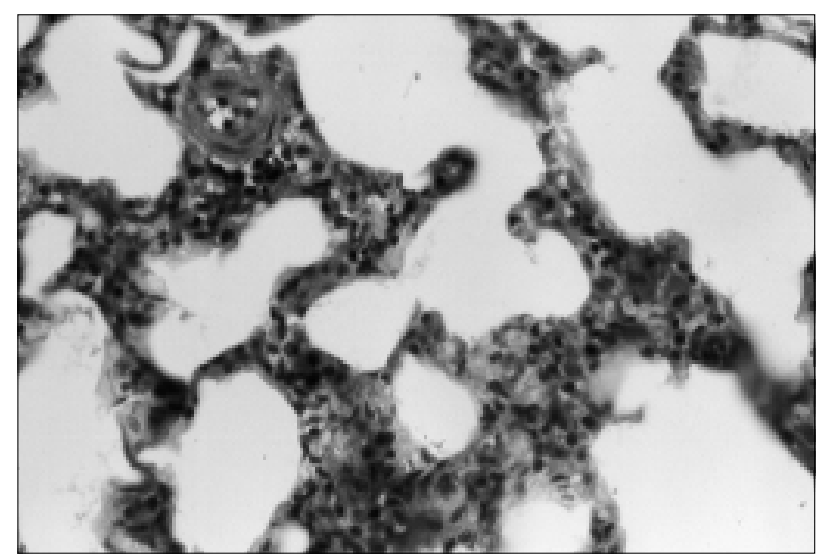

Figura 2 - Presença de leucócitos nos septos alveolares do rato $n^{\circ} 2$ do grupo I. $40 X$.

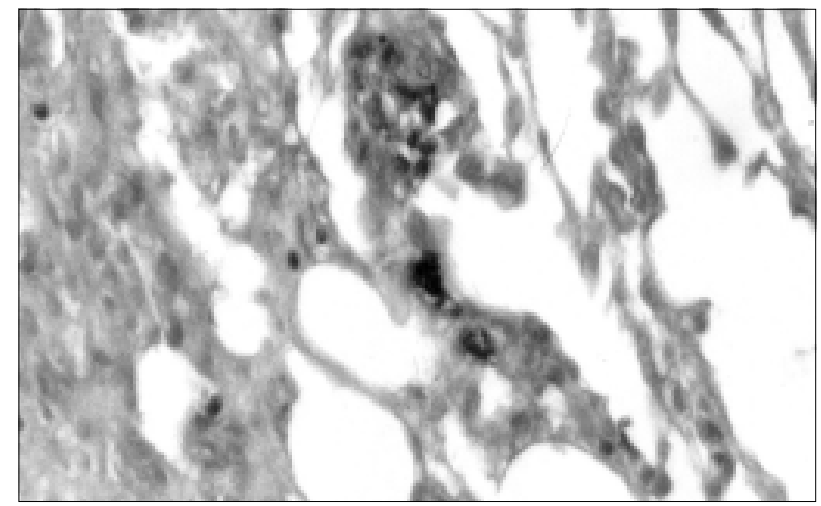

Figura 4 - A coloração específica mostrou bactérias Gramnegativas no septo alveolar do rato $n^{\circ} 6$ do grupo I. 40X.

troles e, nesses animais ictéricos, que apresentavam alta população bacteriana, ocorreu translocação para linfonodos mesentéricos ${ }^{17}$. Outros autores têm demonstrado que os ácidos biliares são capazes de fragmentar as moléculas de endotoxinas liberadas pelos germes entéricos, implicando que a ausência deles na luz intestinal permite que endotoxinas permaneçam intactas para absorção ${ }^{7,20,21}$. Os germes mais comumente encontrados nos órgãos extra-intestinais têm sido E. coli, Klebsiella sp, Pseudomonas aeruginosa, Staphilococcus epidermidis, Candida albicans e os Enterococos 22

Para Deitch et $\mathrm{al}^{3} \mathrm{o}$ mais provável mecanismo da translocação bacteriana no ictérico é a lesão da barreira mucosa do intestino provocada pelo aumento da população de microrganismos intraluminais, que resulta, como observado em seu estudo, em edema de vilosidades e lesão da lâmina própria. Uma vez lesada a barreira mucosa, os germes e as endotoxinas atingem a lâmina própria, são fagocitados pelos macrófagos e chegam aos linfonodos mesentéricos. Daí podem alcançar o ducto torácico, as veias do sistema porta, fígado e os pulmões, ganhar a circulação sistêmica e atingir outros órgãos. A obstrução biliar extrahepática induz à depressão do sistema imunológico ${ }^{23}$. Gra- 
ve et $\mathrm{al}^{24}$ sugeriram que ocorre depressão na função das células T na endotoxemia sistêmica e os linfócitos T situados na mucosa gastrintestinal, nas placas de Peyer e nos linfonodos mesentéricos têm um papel importante na prevenção da translocação bacteriana ${ }^{25}$. Alem disso, ocorre uma alteração no sistema fagocitário dos mononucleares e dos macrófagos em animais ictéricos ${ }^{26}$.

A infecção pulmonar é uma complicação pós-operatória comum e tem ocorrido na vigência de contaminação por bactérias viáveis em acometimento de vias biliares, mesmo sob condições estéreis ${ }^{27}$. A inflamação da mucosa do trato respiratório pode reduzir sua eficácia como uma barreira à infecção e alterar a permeabilidade alveolocapilar. A permeabilidade da barreira alveolocapilar pode ser destruída tanto diretamente pelas toxinas das bactérias entéricas translocadas, quanto por mediadores liberados de macrófagos ativados ${ }^{28}$. A suscetibilidade dos pulmões pode ser induzida pela geração de radicais livres, reações em cadeia, oxidação destrutiva, leucócitos inflamatórios e substâncias liberadas de células inflamatórias ${ }^{29}$. Os resultados do atual estudo mostraram a presença de bactérias Gramnegativas nos pulmões de ratos ictéricos, o que pode explicar as alterações histopatológicas observadas mais intensamente nos animais em que ocorreu a translocação. Concluiu-se que a icterícia obstrutiva por ligadura do colédoco em ratos provocou translocação de germes Gramnegativos para os pulmões, repercutindo na sua histologia de modo significativo.

\begin{abstract}
Background: It has been demonstrated that obstructive jaundice provokes depression of the immunologic system, changes the pattern of intestinal bacterial colonization and possibly permits bacterial translocation lumen to the portal and systemic circulations. An experimental study performed done in rats to assess the incidence of enteric bacteria translocation to the lungs after choledocus closure. Method: Twenty Wistar male rats weighing 178 to $215 \mathrm{~g}$ were randomly assigned to 2 groups. In group $I,(n=10)$ it the choledocus was tied with 0000 silk suture and in group II the choledocus was manipulated with atraumatic instrument (sham operation). In the 7th day the animals were killed with anesthetic overdose, blood sample was colected for bilirrubin dosage and the lungs were ressected under aseptic conditions. Half of each lung was homogenized and cultured in agar McConkey and agar blood. The other half was processed by conventional histologic methods. The sections were cut and stained by Gram, haematoxilin and eosin and examined with light microscopy. Data were analyzed by t test

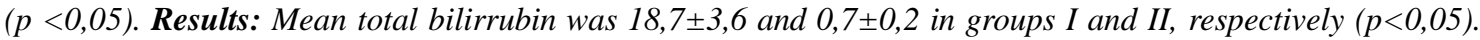
Colonies of Klebsiela sp were isolated in the lungs of $30 \%$ and E. coli in $20 \%$ of group I, and histopathological scores presented an average of 6.2 22.08. No bacteria was detected in the lungs of group II and the scores histopathological reached 1,8 1,16 ( $p<0,05)$. Conclusions: Obstructive resulting jaundice in rats promotes translocation of Gram negative bacteria to the lungs, resulting in significant histopatologic alterations.
\end{abstract}

Key Words: Bacterial translocation; Lungs; Obstructive jaundice.

\title{
REFERÊNCIAS
}

1. Drivas G, James O, Wardle N. Study of the reticuloendothelial phagocytic capacity in patients with cholestasis. Br Med J 1976, 1: 1568-1569..

2. Clements WDB, Halliday MI, McCaigue MD, et al. The effects of extrahepatic obstructive jaundice on Kupffer cell clearance capacity. Arch Surg 1993, 128(2):200-203

3. Deitch E A, Sittig K, Berg R, et al. Obstructive jaundice promotes bacterial translocation from the gut. Am $\mathrm{J}$ Surg 1990, 159(1):79-84.

4. Ding JW, Andersson R, Soltesz V, et al. Obstructive jaundice impairs reticuloendothelial function and promotes bacterial translocation in the rat. J Surg Res 1994, 57(2): 238-245.

5. Medeiros A C, Sousa Z M, Lins M R S, et al. Icterícia obstrutiva experimental e profilaxia da insuficiência renal. Rev Col Bras Cir 1995, 22(2): 279-283.

6. Cahill CJ, Pain JA, Bailey ME. Bile salts, endotoxin in renal function in obstructive jaundice. Surg Gynecol Obstet 1987, 165(4): 519-522.
7. Kocksar LT, Bartok L. Effects of bile acids on the intestinal absorption of endotoxins in rats. J Bacteriol 1969, 100(1): 220-223.

8. Berg RD, Garlington AW. Translocation of certain indigenous bacteria from the gastrointestinal tract to the mesenteric linfonodes and the other organs in a gnotobiotic mouse model. Infec Immun 1979, 23(3): 40341.

9. Deitch EA, Berg R, Specian R. Endotoxin promotes the translocation of bacteria from the gut. Arch Surg 1987, 122(1): 185-190.

10. Su CH, P'eng FK, Lui WY. Factors affecting morbidity and mortality in biliary tract surgery. World J Surg 1992, 16(4): 636-540.

11. Wait RB, Kang KU. Renal failure complicating obstructive jaundice. Am J Surg 1989, 157(1): 256-263.

12. Hunt DR, Allison MEM, Prentice CRM, et al. Endotoxaemia disturbance of coagulation and obstructive jaundice. Am J Surg 1982, 144(2): 325-329. 
13. Berg RD, Wommack E, Deitch EA. Immunossupression and the intestinal overgrowth synergistically promotes bacterial translocation. Arch Surg 1988, 123(6): 13591364.

14. Deitch EA, Bridges RM. Effect of stress and trauma on the bacterial translocation from the gut. J Surg Res 1987, 42(4): 536-542.

15. Holman JM. Rikers LF, Mooddy .G. Sepsis in the management of complicated biliary disorders. Am J Surg 1979, 138(5): 809-813.

16. Kats S, Grosf LD, Cross K. Impaired bacterial clearance and trapping in obstructive jaundice. Ann Surg 1984, 199(1): 14-20.

17. Clements WDB, Parks R, Erwin P, et al. Role of the gut in the pathophysiology of extrahepatic biliary obstruction. Gut 1996, 39(4): 587-597.

18. Bergesen O, Schjonsby H, Andersen KJ, et al. Intestinal epithelial function and villous surface area in rats with bile fistulae. Scand J Gastroenterol 1987, 22(5):731736.

19. Brown TH, Walton G, Cheacle WG, et al. The alcaline shift in gastric pH after cholecystectomy. Am J Surg 1989, 157(1): 58-65.

20. Fletcher MS, Westwick J. Endotoxins, prostaglandins and renal fibrin deposition in obstructive jaundice. $\mathrm{Br} \mathrm{J}$ Surg 1982, 69(4): 625-629.

21. Evans HJR, Torrealba V, Hudd C. The effect of preoperative bile salts administration on postoperative renal function in patients with obstrutive jaundice. Br J Surg 1982, 69(5): 706-708.

22. West MA, Keller GA, Hylland BJ. Hepatocyte function in sepsis: Kuppfer cells mediate a biphasic protein synthesis response in hepatocytes after exposure to endotoxin or killed E. coli. Surgery 1985, 98(2): 388394.

23. Vane DW, Redlich P, Weber T, et al. Impaired immune function in obstructive jaundice. J Surg Res 1988, 45(2): 287-293.

24. Greeve J W, Gouma DJ, Soeters PB, et al. Suppression of cellular immunity in obstructive jaundice is caused by endotoxins: A study with germ free rats. Gastroenterology 1990, 779(3): 478-485.
25. Gautreaux MD, Deitch EA, Berg RD. T-Lynphocytes in host defence against bacterial translocation from the gastrointestinal tract. Infect Immun 1994, 62(6): 28742884.

26. Scott-Conner CE, Groogan JB. The pathophysiology of biliary obstruction and its effect on phagocitic and immune function. J Surg Res 1994, 57(2): 316-336.

27. Wang X D, Wang Q, Soltesz V, et al. Pulmonary infections of gut origin after major liver resection in rats. Eur J Surg 1993, 159(2): 399-404.

28. Wang XD, Andersson R, Soltezs V, et al. Bacterial translocation from the gut following major hepatectomy in patients and rats. Arch Surg 1992, 127(6): 1101-1106.

29. Boucher RC, Van Scott MR, Willumsen N, et al. Epithelial injury. Mechanisms and cell biology of airway epithelial injury. Am Rev Respir Dis 1988, 138(1): S41S44.

Endereço para correspondência:

Aldo da Cunha Medeiros

Av. Miguel Alcides Araújo 1889

59078-270 - Natal-RN 